\title{
A scientific note on the effect of centrifugation on pooled honey bee semen
}

\author{
Anita M. COLLINS* \\ Bee Research Laboratory, ARS, USDA, 10300 Baltimore Ave., Bldg. 476 BARC-East, Beltsville, MD 20705, USA
}

(Received 11 January 2002; revised 13 December 2002; accepted 18 December 2002)

pooled semen / centrifugation / honey bee spermatozoa / fluorescent stain / viability

The ability to pool semen from many drones and then use it for artificial insemination (AI) is a valuable tool for honey bee, Apis mellifera, breeding as it reduces the rate of inbreeding and results in a greater effective breeding population (Page and Laidlaw, 1982). Several authors have reported pooling semen (Taber, 1961; Poole and Taber, 1969; Kaftanoglu and Peng, 1980), including some who also deliberately mixed it (Moritz, 1983; Harbo, 1990). In all cases, the semen was also centrifuged. Using a live:dead dual fluorescent staining technique (Collins and Donoghue, 1999), we found unacceptably low viability $(34.1 \%$, unpublished data) in semen mixed and centrifuged in a manner similar to Moritz and Harbo. Therefore, a study was undertaken to determine the optimum centrifugation conditions of pooled, honey-bee semen to be used for AI.

Mature, free-flying drones were stimulated to ejaculate by the standard method and the semen collected with a Harbo syringe (Harbo, 1974) into glass capillary tubes. For each sample, the semen was mixed by inversion in Kiev buffer (Moritz, 1984) in an eppendorf tube, subdivided and centrifuged as dictated by experimental design, and the pellet resuspended in $800 \mu \mathrm{L}$ of fresh buffer. Observations were made on the compactness of the pellet, the ease of removal of the supernatant and ease of resuspension of the pellet. A $200 \mu \mathrm{L}$ aliquot was stained using the protocol of Collins and Donoghue (1999). Two observers counted two or three subsamples each, scoring one hundred cells as live or dead (percent live spermatozoa). Data were analyzed by Analysis of Variance, using Proc GLM (SAS Institute, 1988).

Ten semen samples (5-8 drones) were used to determine that holding samples for $5 \mathrm{~m}, 30 \mathrm{~m}$, $60 \mathrm{~min}$ or $120 \mathrm{~min}$ after the staining did not increase the proportion of dead spermatozoa $(F=0.35$; df $=3 ; P=0.7886$; means ranged from $85.1-$ $96.9 \%)$. Seven larger samples (25-35 drones) were collected, diluted and mixed, and divided into 6 equal parts, each of which was centrifuged with a different published speed/time treatment (Tab. IA). A third experiment compared three gentle centrifugation levels across three times (5 replicates of 10 or $30 \mu \mathrm{L}$ semen in 10 subsamples) (Tab. IB).

Centrifugation at speeds of $8160 \mathrm{~g}$ killed a significant number of spermatozoa and produced pellets that were difficult to resuspend. The best results were obtained with speeds of 82 or $250 \mathrm{~g}$ at 20-30 or 10-20 min, respectively. These pellets were easily separated from the supernatant and resuspended in buffer. The numeric differences of percent live spermatozoa seen between the two experiments is due to some aspect of collection and handling of the semen prior to centrifugation. What exactly caused the high mortality in Experiment B has not yet been determined.

Collins (2000) has reported that even queens inseminated with only $50 \%$ live spermatozoa produced normal worker brood, at least early in their lives. Some of the dead spermatozoa were left behind in the vagina during migration to the spermatheca. If 30 or so spermatozoa are released with each egg just after mating (Harbo, 1979), enough live ones would have been present to fertilize the egg successfully. If the mixed semen reported by Harbo (1990), Moritz (1983), and Taber (1961) had levels of viability similar to the treatments here, the normal brood appearance would have hidden the presence of damaged spermatozoa. At least two commercial queen breeders who use mixed semen experienced problems (drone layers and supersedure) and shifted to mechanical stirring (Cobey, personal communication) or slower centrifugation (Kuhnert et al., 1989).

*Corresponding author: collinsa@ba.ars.usda.gov 
Table I. Comparison (least squares means and std. err.) of viability of spermatozoa in semen samples diluted, mixed and centrifuged at various speeds and times. Within each experiment, means with letters are significantly different from the control $(\mathrm{A}: \mathrm{F}=8.72 ; \mathrm{df}=5 ; P=0.0001 ; \mathrm{B}: \mathrm{F}=2.51 ; \mathrm{df}=9 ; P=0.0093)$.

\begin{tabular}{lccc}
\hline Treatment & Speed $-\mathrm{g}$ & Time - min & \% Live sperm \\
\hline Experiment A & & & \\
\hline control & 0 & 0 & $83.4 \pm 1.7$ \\
Collins and Donoghue & 82 & 30 & $84.0 \pm 1.6$ \\
Poole and Taber & 180 & 5 & $81.3 \pm 1.7$ \\
Kaftanoglu and Peng & 510 & 10 & $80.1 \pm 1.6$ \\
Taber & 8160 & 1 & $77.4 \pm 1.7 \mathrm{a}$ \\
Harbo/Moritz* & 8160 & 10 & $70.7 \pm 1.7 \mathrm{a}$ \\
\hline Experiment B & & & \\
\hline control & 0 & 0 & $54.0 \pm 2$ \\
1a. & 82 & 10 & $45.9 \pm 2.5 \mathrm{~b}$ \\
1b. & 82 & 20 & $48.7 \pm 2.8$ \\
1c. & 82 & 30 & $52.9 \pm 2.6$ \\
2a. & 250 & 10 & $50.4 \pm 2.6$ \\
2b. & 250 & 20 & $48.7 \pm 2.7$ \\
2c. & 250 & 30 & $45.5 \pm 2 \mathrm{~b}$ \\
3a. & 510 & 10 & $46.1 \pm 2.5 \mathrm{~b}$ \\
3b. & 510 & 20 & $49.1 \pm 2.5$ \\
3c. & 510 & 30 & $40.9 \pm 2.5 \mathrm{~b}$ \\
\hline
\end{tabular}

* These two studies were combined into a minimum representative speed and time.

Note scientifique sur l'action de la centrifugation sur des échantillons de sperme d'abeilles domestiques mis ensemble.

Eine wissenschaftliche Notiz über die Wirkung der Zentrifugation auf Sammelproben von Sperma der Honigbienen.

\section{REFERENCES}

Collins A.M. (2000) Relationship between semen quality and performance of instrumentally inseminated honey bee queens, Apidologie 31, 421-429.

Collins A.M., Donoghue A.M. (1999) Viability assessment of honey bee, Apis mellifera, sperm using dual fluorescent staining, Theriogenology 51, 1513-1523.

Harbo J.R. (1974) A technique for handling stored semen of honey bees, Ann. Entomol. Soc. Am. 67, 191-194.

Harbo J.R. (1979) The rate of depletion of spermatozoa in the queen honeybee spermatheca, J. Apic. Res. 18, 204-207.
Harbo J.R. (1990) Artificial mixing of spermatozoa from honeybees and evidence for sperm competition, J. Apic. Res. 29, 151-158.

Kaftanoglu O., Peng Y.-S. (1980) A washing technique for collection of honeybee semen, J. Apic. Res. 19, 205-211.

Kuhnert M.E., Carrick M.J., Allan L.F. (1989) Use of homogenized drone semen in a bee breeding program in Western Australia, Apidologie 20, 371-381.

Moritz R.F.A. (1983) Homogenous mixing of honeybee semen by centrifugation, J. Apic. Res. 22 , 249-255.

Moritz R.F.A. (1984) The effect of different diluents on insemination success in the honeybee using mixed semen, J. Apic. Res. 23, 164-167.

Page R.E. Jr., Laidlaw H.H. Jr. (1982) Closed population honeybee breeding. 2. Comparative methods of stock maintenance and selective breeding, J. Apic. Res. 21, 38-44.

Poole H.K., Taber S. III (1969) A method of in vitro storage of honey-bee semen, Am. Bee J. 109, 420-421.

SAS Institute (1988) SAS/STAT User's Guide release 6.03, Cary, NC, Statistical Analysis System Institute.

Taber S. III (1961) Successful shipments of honeybee semen, Bee World 42, 173-176. 